\title{
Build It and They Will Come: Maintaining Students Access to Fabrication and Testing During a Pandemic
}

\author{
Matteo Di Benedetti \\ The University of Sheffield \\ Andrew Garrard \\ The University of Sheffield \\ Stephen BM Beck \\ The University of Sheffield
}

\begin{abstract}
The Civil Engineering curriculum at Sheffield University offers students the opportunity to work in groups to design, build and test models. This fulfils vital learning outcomes for accreditation requirements. The onset of the pandemic restricted the amount of face-to-face teaching. Presented here are methodologies to reconfigure teaching with restricted access to allow learning outcomes to be achieved while keeping students motivated. Traditional hands-on manufacturing and testing were replaced by "service" build and test schemes that hinged around the typical relationship between a designer (students) and a contractor. With the use of screens, PPE and careful communication, fabrication activities simulated an "assembly line" relay rather than the traditional "fixed-position assembly" allowing the activity to safely run faceto-face. Students were able to engage individually and in groups on these teaching methods to execute exciting and real projects, in a way that is scalable to large class sizes (Garrard and Beck, 2018). We explore the advantages and drawbacks of these approaches and suggest elements to be retained when restrictions are lifted.
\end{abstract}

Keywords: blended learning, active learning, making, Covid-19

\section{INTRODUCTION}

Projects in industry often require engineers to operate in teams to design, build and test artefacts. It is important for engineering educators to introduce students (or trainee engineers) to these experiences before they start work. The first year Civil and Structural Engineering curriculum at Sheffield University contains a module (CIV1200 Introduction to Civil and Structural Engineering Design), in the Autumn Semester, where students design, build and test wooden small-scale bridges models working in groups of up to twelve. This provides a series of vital Learning Outcomes (Interpret a project brief, produce a design and present the results) which are also required for professional body accreditation (Engineering Council, 2014).

The design stage of this module is supported with lectures, tutorials and lab activities. The making part of this module takes place towards the end of the semester with students having access to two build facilities 
we refer to as "pop-up project spaces" (PuPS), cabinets on wheels filled with hand tools that students can use with minimal supervision, and the "iForge" Maker Space (Mylon et al., 2019). Load testing is carried out by one member of the teaching team in front of students.

The pandemic reduced the amount of face-to-face teaching across the University, either through suspension of access during "lockdown" or with reduced occupancy due to "social distancing". The iForge suspended support to curricular projects and access to the laboratories was severely curtailed. For example, the Structures Laboratory where the bridge building took place had its capacity slashed from 80 students to 20. Additionally, students needed to stay $2 \mathrm{~m}$ apart, wear face coverings, and workstations had to be sanitised after each use. While mature streaming software allows lectures or seminars to take place remotely, delivering design, build and test activities is more problematic. An innovative solution was needed to reconfigure the module, while maintaining key learning outcomes and keeping the students motivated and, hopefully, happy.

Possible solutions to this problem might include take home labs (Patterson, 2019). Using this approach would require concessions to mitigate issues of equity and health and safety that would negatively impact on the learning experience. It also precludes group working. Another possibility was getting staff on site to do the work, similar to the approach in industry, such as in case study on pilot plant experiments in (Bangert et al., 2020). However, this would reduce the team working aspects of the project as only a few members would engage with the fabrication.

Finally, it should be noted that it was not known how many students would be in Sheffield or aboard, and the availability of technology at home. However, Sheffield University ensures students on all courses have access to appropriate technical support as part of their institutional provision.

\section{METHODOLOGY}

\section{Fabrication of the Components}

Prior to covid-19, fabrication of the model's components required advanced manufacturing (i.e., laser cutting) that took place during the Bridge Building sessions. Students would inspect the cut component, assess if it matched what they intended to design and, when necessary, amend their drawing and have parts cut again. While this optimization cycle is well suited to students with limited experience of laser cutting, this fabrication stage does not suitably represent the working dynamics in industry and the usually high costs of rebuilding erroneously designed components.

During teaching under the social restrictions of Covid-19 a new procedure resembling the typical designer/contractor relationship was introduced. Students (the designers) created files for their parts which were digitally submitted ahead of time. Staff (the contractor) reviewed the files, provided feedback when necessary (so the parts could be redesigned before cutting) and manufactured the parts making them available to students on the day of their timetabled Bridge Building lab session.

\section{Bridge Building}

The Bridge Building session ran for approximately 4 hours and all team members (up to 12 students) cooperated to manufacture components and assemble the final bridge. Time constraint was a key aspect for stimulating students to work as a team, splitting tasks and sharing responsibilities.

Due to social distancing and the decreased occupancy, the format required some changes. Recognising the pedagogical importance of teamwork and of the hands-on experience of building engineered components, it was decided to retain this as a face to face activity. They were designed to simulate an assembly line, with one student from each group accessing one PuPS at a time. Each group had a maximum of 12 hours, with bookable slots of 1 hour. A handover between one team member and the next was used to stimulate teamwork and cooperation. Perspex sheets across the middle of the working station allowed the finishing student to communicate effectively and safely with the new starter. The finishing student, after sanitising the working station, tools and bridge, left the space and the next student took over. To further support teamwork, students were encouraged to use digital devices to remotely connect with other group members to discuss arising problems and also not to feel abandoned. 


\section{Bridge Testing}

The wooden bridges were load tested by hanging weights at the mid-span. Since the bridge is tested to failure, the activity cannot be repeated and consequently it could not be offered to all students in the group as only one could be present. To avoid disparities, it was decided that tests would be carried out by members of staff. Because of the high number of bridge models to test, the option of a synchronous live session was discarded. In fact, it would have not been feasible to perform all the tests at a time suitable to all students as they were often in different time zones, with the consequent risk of alienating some students. Thus, tests were recorded, on videos and these were shared with students along with all the relevant experimental results (total weight, peak load, geometrical dimensions).

\section{RESULTS}

\section{Fabrication of the Components}

Simulating the designer/contractor roles as part of the fabrication stage worked very well for the majority of groups. Only in a few instances were problems in the submitted files (e.g., wrong size, unintended cutting lines) discovered once a student turned up to the bridge building session and assessed the components. While generating some delays in the delivery of the amended parts, this also offered the possibility to provide some feedback to the groups and to create a list of "good practice" instructions for submitting the design file (this will be used in future years). In addition, in one of the groups, the student responsible for the drawing parts was working remotely in a different time zone and was not available at the time of the first Bridge Building session to amend the files. This offered the opportunity to discuss task allocation and redundancy.

\section{Bridge Building}

All groups engaged with the activity and completed their bridges ahead of time. Initial informal feedback suggests the activity was well received with three considerations.

1. Some groups used to their advantage the fact that some students were working in different time zone effectively extending the "working hours" of the group.

2. Students appreciated the time allocated to the handover as it represented, due to the pandemic, the first time they worked with another team member in the lab. In addition, a discussion with a student identified a possible strategy to effectively and timely exchange all necessary information; highlighting an early understanding of the importance of teamwork.

3. One group lamented the limited engagement of some group members which resulted in additional workload and pressure. In future, peer-assessment will be introduced in order to attribute the contribution of all team members fairly.

\section{Bridge Testing}

The asynchronous video recordings of the testing were an effective way to reach out to students and to provide dedicated feedback to each group. On the other hand, the authors believe that running this task remotely has lost some of its traditional excitement and engagement.

\section{CONCLUSIONS}

This module represents an early attempt to use a blended teaching approach to group project work involving the fabrication of an artefact while dealing with the restrictions imposed by the pandemic. Some of the elements herein developed will be retained, in a modified form, for future activities.

1. The assembly line model, optimized to allow two students on each workstation in order to more effectively promote teamwork while social-distancing, has already been rolled out to other modules.

2. The designer/contractor relationship aiming at stimulating the professionalisation of students will be further exploited. 
The philosophy underpinning these two points will become integral part of other lab activities after the end of the pandemic when the original room capacity will be restored.

\section{ACKNOWLEDGEMENTS}

This manuscript was originally published in the open access proceedings of the SEFI 2021 Conference. The authors would like to thank the Chairs of the conference that gave permission for the manuscript to be submitted to this journal.

\section{REFERENCES}

Bangert, K., Bates, J., Beck, S.B., Bishop, Z.K., Di Benedetti, M., Fullwood, J., . . Woolley, R. (2020). Remote practicals in the time of coronavirus, a multidisciplinary approach. International Journal of Mechanical Engineering Education, 0306419020958100.

Engineering Council. (2014). The accreditation of higher education programmes (3rd Ed.). Retrieved April 21, 2021, from https://www.engc.org.uk/engcdocuments/internet/Website/ Accreditation\%20of\%20Higher\%20Education\%20Programmes\%20third\%20edition\%20(1).pdf

Garrard, A., \& Beck, S. (2018). Pedagogical and cost advantages of a multidisciplinary approach to delivering practical teaching. The Interdisciplinary Future of Engineering Education, pp. 33-48. Routledge.

Mylon, P., Wood, G., \& Dolmansley, T. (2019, July). Using student-led manufacturing in makerspaces to support transition into engineering higher education. In HEAD'19. 5th International Conference on Higher Education Advances (pp. 253-260). Editorial Universitat Politècnica de València.

Patterson, E.A. (2021). Using everyday engineering examples to engage learners on a massive open online course. International Journal of Mechanical Engineering Education, 49(1), 3-24. 